\title{
Cyberbullying and traditional bullying in adolescence: Differential roles of moral disengagement, moral emotions, and moral values
}

\author{
Sonja Perren $^{1}$ and Eveline Gutzwiller-Helfenfinger ${ }^{2}$ \\ ${ }^{1}$ Jacobs Center for Productive Youth Development, University of Zürich, \\ Zürich, Switzerland \\ ${ }^{2}$ Department of Educational Research, University of Teacher Education, \\ Lucerne, Switzerland
}

The aim of this study was to investigate whether different aspects of morality predict traditional bullying and cyberbullying behaviour in a similar way. Students between 12 and 19 years participated in an online study. They reported on the frequency of different traditional and cyberbullying behaviours and completed self-report measures on moral emotions and moral values. A scenario approach with open questions was used to assess morally disengaged justifications. Tobit regressions indicated that a lack of moral values and a lack of remorse predicted both traditional and cyberbullying behaviour. Traditional bullying was strongly predictive for cyberbullying. A lack of moral emotions and moral values predicted cyberbullying behaviour even when controlling for traditional bullying. Morally disengaged justifications were only predictive for traditional, but not for cyberbullying behaviour. The findings show that moral standards and moral affect are important to understand individual differences in engagement in both traditional and cyberforms of bullying.

Keywords: Bullying; Cyberbullying; Moral disengagement; Moral values; Moral emotions.

It has been repeatedly argued that bullies may have deficits regarding their morality (Hymel, Schonert-Reichl, Bonanno, Vaillancourt, \& Henderson, 2010). Recent integrative models in developmental moral theory have

Correspondence should be addressed to Sonja Perren, Jacobs Center for Productive Youth Development, University of Zürich, Culmannstrasse 1, CH-8006 Zürich, Switzerland.

E-mail: perren@jacobscenter.uzh.ch 
emphasized the need to investigate both moral cognition and moral affect in understanding individual differences in behaviours such as bullying (Arsenio \& Lemerise, 2004; Malti \& Latzko, 2010). We differentiate between two types of bullying: traditional bullying, including physical or verbal harassment, exclusion, relational aggression; and cyberbullying, involving the use of some kind of electronic media (i.e., internet or mobile phone) to engage in bullying behaviour. There is a significant conceptual and empirical overlap between both types of bullying (Dooley, Pyzalski, \& Cross, 2009; Smith \& Slonje, 2010). Nevertheless, it remains unclear whether similar psychological processes account for the occurrence of both types of bullying behaviour. The aim of the current study was to investigate the associations between both types of bullying and different indicators of morality in adolescents (morally disengaged justifications, feeling of remorse, and moral values).

\section{Moral disengagement as a framework for understanding bullying}

In the moral domain, Bandura's social cognitive theory of human agency offers an inclusive conceptual framework within which the moral dimensions of bullying can also be described. According to this framework, individuals' moral standards are used in a self-regulatory process to evaluate the potential consequences of intended behaviour for themselves. If - by violating their moral standards - self-condemnation (i.e., guilt) is anticipated, the behaviour is not realized (Bandura, 2002). However, it is possible for individuals to enact behaviours that are not concordant with their moral standards without feeling guilty. To achieve this, individuals use cognitive mechanisms that can be selectively activated in order to escape negative selfevaluations and self-sanctions and thus allow them to morally disengage themselves from adherence to moral standards. According to this approach, moral values (standards), moral emotions, and moral justifications (cognitions) are important in understanding bullying behaviour.

\section{Moral disengagement and bullying}

A few studies in children and adolescents have used the conceptual framework of moral disengagement to investigate moral reasoning patterns among bullies. Several studies have shown that bullying is positively associated with self-reported moral disengagement in adolescents (Hymel, Rocke-Henderson, \& Bonanno, 2005; Obermann, 2011) and in children (Gini, 2006; Gini, Pozzoli, \& Hauser, 2011). A recent study by Pornari and Wood (2010) showed that moral disengagement is not only associated with traditional peer aggression but also with cyber aggression. A few studies have also used production measures to assess children's and adolescents' moral disengagement strategies and their associations with bullying. 
Children and adolescents were asked to produce emotion attributions and justifications to a perpetrator in a hypothetical story. These studies showed that children (Perren, Gutzwiller-Helfenfinger, Groeben, Stadelmann, \& von Klitzing, 2009) and adolescents (Perren, Gutzwiller-Helfenfinger, Malti, \& Hymel, 2011) who were more frequently involved in bullying produced more morally disengaged and less morally responsible justifications. Bullies justified the moral transgression of a hypothetical bully mainly from an egocentric point of view, and their thinking centred on receiving personal benefit and profiting from their negative actions (Menesini et al., 2003).

\section{Moral emotions and bullying}

Moral emotions have been considered as mediators between moral standards and moral behaviour (see Tangney, Stuewig, \& Mashek, 2007). They help children anticipate the negative outcomes of moral transgressions and enable them to adjust their moral behaviour accordingly (Malti, Gasser, \& Buchmann, 2009).

Moral emotions have been intensively researched in the context of the happy victimizer paradigm. The "happy victimizer" describes a phenomenon in which there is a discrepancy between young children's understanding of moral rules and their attribution of positive emotions to perpetrators (Krettenauer, Malti, \& Sokol, 2008). These studies showed significant associations between moral emotion attributions (i.e., emotions attributed to a perpetrator) and aggressive behaviour. A different line of research has investigated associations between moral emotions such as shame and guilt and their relation to moral behaviour (see Tangney et al., 2007).

Only a few studies have investigated the specific link between bullying and moral emotions. A study by Menesini and collaborators (2003) showed that bullies attributed pride and indifference to the perpetrator more frequently than did either victims or uninvolved children. A study by Ttofi and Farrington (2008) showed that positive shame management (i.e., a high level of acknowledgement of feelings of shame and remorse and a low level of shame displacement) was negatively associated with bullying. Likewise, Menesini and Camodeca (2008) reported negative associations between bullying and guilt and shame.

In sum, studies involving different methods and approaches have consistently indicated that bullying is associated with lower levels of moral emotions like guilt and shame and higher levels of emotions like pride or indifference in the context of moral transgressions, respectively.

\section{Moral values and bullying}

Besides moral emotions and moral disengagement strategies, the normative area (i.e., moral values, norms, standards, and beliefs) is also important to 
consider in attempts to explain the moral side of bullying. Moral standards are actively employed in exercising moral agency (Bandura, 2002; Blasi, 2001). However, moral values are not the only values individuals hold and adhere to. According to Schwartz (2006), individuals adapt their values to their life circumstances, upgrading the importance of those they can easily attain and downgrading the importance of those they cannot (easily) pursue.

Several studies have demonstrated a strong link between bullying behaviour and general pro-bullying or pro-aggression attitudes or norms (e.g., Salmivalli \& Voeten, 2004). Laible, Eye, and Carlo (2008) identified the level of internalization of moral values as one aspect of moral cognition, which is negatively associated with bullying behaviour. However, our knowledge about these associations is rather limited, and we need research to assess the role of both endorsement and prioritizing of moral and other values in relation to bullying.

\section{The specific role of morality in cyberbullying}

As outlined above, morality is an important aspect to consider when explaining the occurrence of bullying behaviour. Most studies have investigated these associations in relation to traditional bullying. Only a few studies have investigated this link with respect to cyberbullying.

Although there is a high degree of empirical and conceptual overlap between traditional and cyberbullying, specific distinct features have been identified (Dooley et al., 2009; Smith et al., 2008). With respect to morality, the potential invisibility of the victim might be a specific feature of cyberbullying that is important to consider. Through the use of electronic forms of aggressive contact (cell phone, internet), there is an increased probability that the bully does not directly see the emotional impact of his/her actions on the victim. Because of this absence of direct contact it has been hypothesized that cyberbullying might make it easier for the bully both to act immorally without feeling guilty (Slonje \& Smith, 2008) and to apply cognitive strategies to dissociate him/herself from moral responsibility (Almeida, Marinho, Esteves, Gomes, \& Correia, 2008). However, as this applies also to indirect aggression (e.g., gossiping), the victims' invisibility may not be a specific feature of cyberbullying (Sticca \& Perren, 2010). Nevertheless, the question emerges whether moral issues are more or less relevant to explain cyberbullying in comparison to traditional bullying. More specifically, we might ask whether there are differential effects of different indicators of morality (i.e., affect or cognitions) that are related to traditional forms or cyberforms of bullying, respectively. 
On the other hand, it has been found that most cyberbullies also use more traditional forms of bullying (Raskauskas \& Stoltz, 2007). Those "combined" bullies are bullying others with a larger repertoire of negative actions and maybe also bully more frequently (Perren \& Sticca, 2011). Several studies have indicated that cyberbullies show more severe patterns of maladjustment than those who use only traditional forms (e.g., Gradinger, Strohmeier, \& Spiel, 2009). Therefore, we might hypothesize that cyberbullies have stronger deficits in morality than bullies who engage in traditional forms only.

\section{Research questions}

Previous studies have suggested that bullying behaviour may be predicted by deficits in moral values, moral emotions (lack of remorse), and/or or morally disengaged justifications (cognitions). The aim of the current study was first to investigate whether those different indicators of morality predict traditional and cyberbullying in a similar way. We hypothesized significant positive associations between traditional bullying and cyberbullying (overlap) and significant associations between both types of bullying with higher moral disengagement, lower moral emotions, and lower moral values. As most cyberbullies also use traditional means of bullying, we also investigated whether morality specifically predicted cyberbullying when controlling for traditional bullying behaviour.

Due to developmental trends in bullying and morality we also investigated age differences. Traditional bullying decreases during adolescence, whereas cyberbullying increases over the years of secondary school (Smith \& Slonje, 2010). Regarding morality, developmental trends indicate that children increasingly understand morally relevant situations like transgressions, judge them as wrong, and are able to anticipate the emotions of the persons involved (Krettenauer et al., 2008). However, only in older adolescence is morality fully integrated into the self, and individuals strive to maintain (personal) moral consistency and integrity (Blasi, 2001). Thus, we also investigated whether age moderates the associations between morality and bullying.

In addition, we analysed the role of gender. As far as gender differences are concerned, most studies agree that traditional bullying is more frequent in males (Stassen Berger, 2007), but results for cyberbullying are controversial (Smith \& Slonje, 2010). Based on previous research, we also expected that females would show more moral emotions and less moral disengagement than males (Paciello, Fida, Tramontano, Lupinetti, \& Caprara, 2008; Perren et al., 2011; Tangney et al., 2007). In addition to these main effects of gender, we also explored whether gender moderates the investigated associations. 


\section{METHOD}

\section{Procedure}

A link to an online questionnaire (NetQ) was posted on a large social networking site for German-speaking students (SchülerVZ). SchülerVZ is accessible to students (who must be attending some sort of school) between 12 and 21 years of age. The link was placed online for three hours during one Wednesday afternoon (which is out of school hours) in November 2009. Thus, the sample represents a self-selected sample of students who were active users of this social networking site.

Before completing the questionnaire, students were informed about the goals of the study and gave their informed consent. As in anonymous online studies parental consent cannot be obtained, we decided to use a procedure approaching a "terms of use agreement". We informed participants that parental consent was necessary for this study and required participants under 18 years to click whether their parents agreed to their participation in this study. A similar procedure has been used by other studies (e.g., Hinduja \& Patchin, 2008). Students who indicated that their parents did not consent to their participation in the study were not allowed to complete the questionnaire $(N=174)$. An automatic filter option directed them to a page informing them that they could not participate because their parents had not given permission.

In order to protect students' anonymity, only a few person variables were collected (gender, age). We assumed that risks associated with this anonymous online survey were very low. Participation was voluntary and participants were allowed to discontinue at any time or to skip any question. Participating students were offered an incentive of $€ 5$ (in the form of an electronic voucher for legal music download). To receive this voucher, they had to give an e-mail address. E-mail addresses were only used to send the voucher and were saved separately on a secured server. About $10 \%$ of participants actively withheld their contact details.

\section{Participants}

In total, 564 students partly or fully completed the questionnaire. Only adolescents ( $<20$ years) with complete data sets were included in the current paper ( $N=495,47 \%$ females). Participants' age was distributed fairly evenly between 12 and 19 years.

\section{Assessment of traditional and cyberbullying}

Participants reported on the frequency of bullying over the last three months $(1=$ never, $2=$ once or twice, $3=$ once a month, $4=$ once $a$ week, $5=$ almost 
every day). Six items covered traditional and five items cyberbullying behaviours, respectively. Items were introduced by providing a general definition of bullying, which included negative behaviours such as sending or spreading nasty messages or pictures. For the items we did not use the term cyberbullying but we relied on behavioural descriptions. Item order was completely randomized.

A principal component analysis with Varimax rotation including all eleven items yielded two distinct factors (eigenvalue $>1$ ) for traditional and cyberbullying behaviour, respectively. Two items of the traditional bullying scale (threatening and destroying property) loaded equally on both factors and were excluded from the final bullying scales. Mean scores were computed. The traditional bullying scale encompassed four items (verbal aggression; physical aggression; exclusion; gossiping; $\alpha=.77$ ). The cyberbullying scale encompassed five items (sent nasty or threatening e-mails; nasty messages on the internet/to mobile phone; and mean or nasty comments or pictures sent to websites/other students' mobile phones; $\alpha=.89$ ).

To confirm the distinctiveness of the traditional and cyberbullying scale we also computed a confirmatory factor analysis (CFA) including those nine items with two latent factors. The CFA indicated an acceptable model fit: $\chi^{2}=84.7(d f=21) ; C F I=.974 ; R M S E A=.073$ (Kline, 1998). The correlation between both latent factors was rather high: $r=.73$, $p<.001$.

\section{Assessment of indicators of morality}

Moral disengagement. This was assessed through a production measure (Perren et al., 2011). Participants were given two hypothetical aggression scenarios, both describing a student being hurt by another student. The first scenario described an adolescent intentionally misinforming another adolescent about a meeting with friends (exclusion scenario), and the second described an adolescent disseminating embarrassing pictures of a peer (humiliation scenario). Whether the perpetrator of the scenarios used cyber or traditional means for hurting (text message/internet vs. talking/ printed picture) was randomly assigned (Sticca \& Perren, 2010). Both vignettes were followed by questions assessing participant's moral rule understanding (Q1: "Is it right to give wrong directions or not?" "Why?"); emotion attributions to hypothetical victimizer (Q2: "How does he/she feel?" "Why?"); moral evaluation of emotion attributions to hypothetical victimizer (Q3: "Is it right or not that he/she feels this way?" "Why?"); and moral evaluation regarding self as hypothetical perpetrator (Q4: "How would you feel?" "Why?"; see Malti et al., 2009). Moral justifications 
were established on the basis of students' written answers to the "why" questions.

Based on Menesini et al.'s (2003) conceptual model, we differentiated between morally responsible and disengaged justifications. For the current paper, only disengaged justifications referring to participants' own personal moral evaluations (Questions 1, 3, and 4) were used. Disengaged justifications included egocentric disengagement (e.g., hedonistic reasoning, euphemistic language, minimizing/distorting consequences); deviant rules (e.g., moral justifications, attributions of blame, advantageous comparisons, displacement or diffusion of responsibility); as well as dehumanization of the victim (see also Menesini et al., 2003).

Written answers were coded by two independent raters who were blind toward other data, $20 \%$ of interviews were coded by both. Inter-rater agreement was rather high $(\mathrm{ICC}$, single measure $=.827)$. Mean scores of all three questions across both scenarios were computed (6 questions; $\alpha=.62$ ).

Moral emotions (remorse). These were assessed through self-reports of feelings of remorse/guilt regarding 10 different (cyber)aggression scenarios $(\alpha=.93)$ : "If you had done this, would you have a guilty conscience?" $(1=$ not at all to $5=$ extremely $)$.

Moral values. These were assessed through a 6-item self-report measure $(\alpha=.77)$. Students completed the Ideal Self Value Ratings (Campbell, 2004; Pratt, Hunsberger, Pancer, \& Alisat, 2003). Students were asked to what extent they thought that each of a set of 12 values "should be important for them in their lives" (e.g., "Fair and just: Treat all people equally; don't put people down"). Six of these values were prototypically moral in nature (including trustworthy, good citizen, honest/truthful, kind and caring, fair and just, shows integrity), and could be used as a general index of commitment to a moral valuing self (Campbell, 2004).

\section{RESULTS}

\section{Descriptive statistics and gender differences}

As all scales were skewed, we used non-parametric tests for statistical analyses. Table 1 shows means and standard deviations of all variables divided by gender. A Kruskal-Wallis test showed significant gender differences regarding traditional bullying and all indicators of morality, but not regarding cyberbullying. Boys reported higher levels of bullying, lower levels of moral values, moral emotions (remorse), and produced more disengaged justifications. 


\section{Bivariate associations}

To analyse bivariate associations, Spearman correlations were computed (Table 2). No significant associations emerged between age, morality, and bullying. Traditional and cyberbullying were positively correlated. Both types of bullying showed significant negative associations with moral values, moral emotions (remorse), and positive associations with disengaged justifications.

\section{Multivariate analyses}

In the following analyses, we accounted for the non-normality of the dependent variables through $\log$ transformations and the use of tobit regressions (Osgood, Finken, \& McMorris, 2002).

TABLE 1

Descriptive results by gender

\begin{tabular}{|c|c|c|c|c|c|}
\hline & \multirow[b]{2}{*}{ Scale } & \multirow{2}{*}{$\frac{\text { Girls }(N=243)}{M(S D)}$} & \multirow{2}{*}{$\frac{\operatorname{Boys}(N=252)}{M(S D)}$} & \multicolumn{2}{|c|}{$\begin{array}{l}\text { Gender differ- } \\
\text { ences }\end{array}$} \\
\hline & & & & $\chi^{2}$ & $p$ \\
\hline \multicolumn{6}{|l|}{ Bullying } \\
\hline Traditional bullying & $1-5$ & $1.61(0.71)$ & $1.85(0.92)$ & 8.12 & .004 \\
\hline Cyberbullying & $1-5$ & $1.15(0.47)$ & $1.14(0.44)$ & 0.11 & .741 \\
\hline \multicolumn{6}{|l|}{ Morality } \\
\hline Disengaged justifications & $0-1$ & $0.07(0.13)$ & $0.16(0.21)$ & 33.8 & $<.001$ \\
\hline Moral emotions (remorse) & $1-5$ & $3.94(0.84)$ & $3.44(0.94)$ & 38.8 & $<.001$ \\
\hline Moral values & $1-5$ & $4.31(0.61)$ & $4.14(0.66)$ & 11.8 & .001 \\
\hline
\end{tabular}

Note: Non-parametric test: Kruskal-Wallis.

TABLE 2

Bivariate associations

\begin{tabular}{lccccc}
\hline & $\begin{array}{c}\text { Traditional } \\
\text { bullying }\end{array}$ & $\begin{array}{c}\text { Cyberbullying } \\
\text { Justifications }\end{array}$ & $\begin{array}{c}\text { Emotions } \\
\text { values }\end{array}$ \\
\hline Traditional bullying & -.025 & -.068 & .051 & .070 & .039 \\
Cyberbullying & - & $.399^{* *}$ & $.324^{* *}$ & $-.402^{* *}$ & $-.311^{* *}$ \\
Disengaged justifications & & - & $.138^{* *}$ & $-.320^{* *}$ & $-.205^{* *}$ \\
Moral emotions (remorse) & & - & $-.352^{* *}$ & $-.306^{* *}$ \\
Moral values & & & - & $.475^{* *}$ \\
\hline
\end{tabular}

Notes: Spearman correlations, two-tailed; $* * p<.01(N=495)$. 
In a first set of analyses main effects of morality indicators were tested on (a) traditional bullying, (b) cyberbullying, and (c) on cyberbullying when controlling for traditional bullying. In a second set of analyses, age and gender interactions were included.

Morality predicting traditional bullying and cyberbullying. Tobit regressions indicated that low levels of moral values and of moral emotions and high levels of disengaged justifications predicted higher levels of traditional bullying. Low levels of moral values and moral emotions also predicted higher levels of cyberbullying; both effects remained significant when controlling for traditional bullying (see Table 3).

Age group and gender as moderators. In a second series of tobit regressions, we added age and gender as interaction effect. Age was included in the analysis as linear variable. The analysis yielded no significant interaction effects.

\section{DISCUSSION}

In agreement with other studies (Smith \& Slonje, 2010), we found a high overlap between traditional and cyberbullying. All measures of morality were significantly associated with both traditional and cyberbullying, showing a consistent picture and confirming previous research. Both lower commitment to a moral valuing self and lower feelings of remorse predicted higher levels of traditional bullying and cyberbullying, respectively. The predictive effect of moral emotions and moral values on cyberbullying was especially pronounced and remained significant even when traditional bullying was controlled for. In contrast, higher levels of disengaged justifications predicted higher levels of traditional bullying, but were not

TABLE 3

Morality predicting traditional bullying and cyberbullying (tobit regression)

\begin{tabular}{lccc}
\hline & Traditional bullying & Cyberbullying (1) & Cyberbullying (2) \\
\hline Age & .004 & -.061 & -.064 \\
Sex (being male) & .013 & -.082 & -.088 \\
Disengaged justifications & $.161^{* *}$ & .023 & -.056 \\
Moral emotions (remorse) & $-.273^{* *}$ & $-.302^{* *}$ & $-.156^{*}$ \\
Moral values & $-.197^{* *}$ & $-.205^{* *}$ & $-.115^{*}$ \\
Traditional bullying & & & $.454^{* *}$ \\
Explained variance $\left(R^{2}\right)$ & $.248^{* *}$ & $.198^{* *}$ & $.337^{* *}$ \\
\hline
\end{tabular}

Notes: Cyberbullying was used twice as dependent variable: without (1) and with (2) controlling for traditional bullying. ${ }^{* *} p<.01 ;{ }^{*} p<.05$. Cells show standardized coefficients. 
associated with cyberbullying. These findings indicate that in spite of the high overlap between traditional and cyberbullying, and in spite of consistent associations between both bullying forms and morality, differential patterns exist when it comes to associations between moral disengagement, moral emotions and moral values. With respect to moral disengagement, higher levels of disengaged justifications did not predict higher levels of cyberbullying. It seems that not seeing the victim suffer makes the use of cognitive distancing strategies unnecessary instead of making it easier to use these strategies, as Almeida et al. (2008) suggested. Our finding is line with a study by Bauman and Pero (2011), which also reported non-significant associations. However, other studies such as Pornari and Wood (2010) or Bauman (2010) did find significant associations between cyberbullying and moral disengagement. These inconsistencies may be related to different measures and certainly need further exploration in future research.

With respect to moral emotions, the present results suggest pronounced predictive power of remorse on cyberbullying. We may speculate that the absence of direct contact between perpetrator and victim lowers the cyberbully's emotional engagement regarding feelings of remorse. Like empathy, remorse is an indicator of an individual's awareness of the negative consequences of harmful acts for the victim and thus acts as a mediator between moral standards and moral behaviour (cf. Tangney et al., 2007). Moreover, if no remorse is anticipated as a result of harassing others via electronic media (e.g., because the behaviour is in line with a person's lack of moral values), then, of course, disengagement strategies become unnecessary. Thus, our findings for disengagement strategies, moral values and remorse in the context of cyberbullying can be integrated into the same explanatory framework.

\section{Strengths and limitations}

In our study we used an online questionnaire. Accordingly, we had no direct control over data quality. As we recruited participants from a population of regular users of a specific student social networking site, we had a selfselected sample of this group of adolescents. Furthermore the study was described as being on "coping with cyberbullying", and victims of bullying were therefore overrepresented in our sample (Perren, 2011).

The sampling procedure used entailed two major drawbacks. First, it meant that parental consent could not be obtained. Although the "terms of use agreement" approach was intended to meet this difficulty, it cannot be regarded as fully corresponding with direct parental consent. However, the most ethical course of action, i.e., gaining parents' written informed consent, is often difficult to accomplish in on-line research (see Stern, 2004). Second, 
the self-selection of the sample may have resulted in the over- or underrepresentation of critical participant characteristics. Birnbaum (2004) states that data collected in an on-line study cannot be assumed to represent a sample of some stable population of "web users" and that self-selected web participants cannot be assumed to represent random samples of any particular population. In order to jointly address these two issues in future research and still use the internet with its rich potential to better understand adolescents (Stern, 2004), a different approach needs to be developed. One potential solution might be to use a step-by-step procedure including invited accessibility (Nosek, Banaji, \& Greenwald, 2002) by contacting a randomly selected sample of participants from a school district and providing them with both a unique access code and a link. In a first step, teachers from a randomly selected sample of classrooms are asked to gain informed consent from parents. Those adolescents for whom parental consent is given constitute a pool from which actual participants are randomly selected and contacted. However, such a procedure means that schools and teachers need to be willing to assist in the research and requires careful embedding of the study within the curriculum, e.g., as an assignment in media competence. By afterwards explaining this sampling procedure and the necessity of obtaining parental consent to all students, teachers can sensitize them to the degree of protection owed to them while they are under age, both generally and with respect to research participation.

One of the strengths of our study is the inclusion of participants from early to late adolescence. However, we did not find expected age trends regarding bullying and morality. Moreover, we did not find moderating effects of age on the investigated associations. This lack of associations might be due to self-selection of participants. Further longitudinal research should tap more into developmental processes. As cyberbullying seems to have a peak in middle adolescence, further studies should also investigate non-linear developmental trends. As this question was beyond the scope of the current study, we only tested linear age trends.

In our study, we used different indicators of morality to explain the occurrence of (cyber)bullying. Although most of the measures include adolescents' self-reports, one strength of our study lies in the use of a production measure to assess adolescents' moral justifications instead of a self-report questionnaire on moral disengagement. For the assessment of morally disengaged justifications and moral emotions we used a scenario approach, i.e., participants indicated their hypothetical cognitions and emotions regarding specific (cyber)aggression situations. This approach was chosen to tap into participants' feelings and cognitions regarding specific situations. As we did aggregate answers from different scenarios, we mainly assessed participants' general proneness to moral disengagement or feelings of remorse. In order to investigate distinct psychological processes that 
might be associated with cyberbullying versus traditional bullying, future studies should also apply experimental approaches. Such approaches should aim to disentangle the role of specific situational features of cyberbullying (e.g., visibility of the victim) versus the role of personal attitudes (e.g., general proneness to moral disengagement; e.g., Sticca \& Perren, 2010).

\section{Conclusion}

In sum, our study showed that moral emotions (i.e., reduced feelings of remorse and guilt) and a low commitment to moral values are especially important to explain adolescents' engagement in both traditional and cyberbullying. The results have also implications for prevention and intervention. As both emotional, values-related, and cognitive aspects of morality predicted bullying (and in part cyberbullying), there is a need for integrative approaches to promote moral growth including a deeper understanding of why (cyber)bullying is morally wrong. Accordingly, a "wide range of moral emotions [need to be introduced] into educational practice in a systematic way" (Malti \& Latzko, 2010, p. 5) and related both to values-related and cognitive facets of moral functioning. Apart from promoting empathy and perspective taking, moral emotions like guilt and shame, pride, indignation, etc., need to be addressed and contextualized within specific (cyber)bullying situations. Adolescents must be given time and room to question easy and common disengagement-friendly and bullying-friendly classroom norms, attitudes, and interaction styles and to both develop and maintain prosocial norms and values.

\section{REFERENCES}

Almeida, A., Marinho, S., Esteves, C., Gomes, S., \& Correia, I. (2008). Virtual but not less real: A study of cyberbullying and its relations with moral disengagement and empathy. Poster presented at the 20th Biennial ISSBD Meeting, Würzburg, 13-17 July 2008.

Arsenio, W. F., \& Lemerise, E. A. (2004). Aggression and moral development: Integrating social information processing and moral domain models. Child Development, 75(4), 9871002.

Bandura, A. (2002). Selective moral disengagement in the exercise of moral agency. Journal of Moral Education, 31(2), 101-119.

Bauman, S. (2010). Cyberbullying in a rural intermediate school: An exploratory study. The Journal of Early Adolescence, 30(6), 803-833.

Bauman, S., \& Pero, H. (2011). Bullying and cyberbullying among deaf students and their hearing peers: An exploratory study. Journal of Deaf Studies and Deaf Education, 16(2), 236-253.

Birnbaum, M. H. (2004). Human research and data collection via the internet. Annual Review of Psychology, 55, 803-832.

Blasi, A. (2001). Moral motivation and society. Internalization and the development of the self. In G. Dux \& F. Welz (Eds.), Moral und Recht im Diskurs der Moderne [Morality and justice in modern age discourse] (pp. 313-329). Opladen, Germany: Leske + Budrich. 
Campbell, K. M. (2004). Moral identity, youth engagement, and discussions with parents and peers. St. Catharines, Ontario, Canada: Brock University.

Dooley, J., Pyzalski, J., \& Cross, D. (2009). Cyberbullying versus face-to-face bullying. A theoretical and conceptual review. Zeitschrift für Psychologie/Journal of Psychology, 217(4), $182-188$.

Gini, G. (2006). Social cognition and moral cognition in bullying: What's wrong? Aggressive Behavior, 32(6), 528-539.

Gini, G., Pozzoli, T., \& Hauser, M. (2011). Bullies have enhanced moral competence to judge relative to victims, but lack moral compassion. Personality and Individual Differences, 50(5), 603-608.

Gradinger, P., Strohmeier, D., \& Spiel, C. (2009). Traditional bullying and cyberbullying: Identification of risk groups for adjustment problems. Zeitschrift für Psychologie/Journal of Psychology, 217(4), 205-213.

Hinduja, S., \& Patchin, J. W. (2008). Cyberbullying: An exploratory analysis of factors related to offending and victimization. Deviant Behavior, 29(2), 129-156.

Hymel, S., Rocke-Henderson, N., \& Bonanno, R. A. (2005). Moral disengagement: A framework for understanding bullying among adolescents. Journal of Social Sciences, Special Issue No. 8, 33-43.

Hymel, S., Schonert-Reichl, K. A., Bonanno, R. A., Vaillancourt, T., \& Henderson, N. R. (2010). Bullying and morality: Understanding how good kids can behave badly. In S. R. Jimerson, S. M. Swearer, \& D. Espelage (Eds.), The handbook of school bullying: An international perspective (pp. 101-118). New York, NY: Routledge.

Kline, R. B. (1998). Principles and practice of structural equation modeling. New York, NY: Guilford Press.

Krettenauer, T., Malti, T., \& Sokol, B. W. (2008). The development of moral emotion expectancies and the happy victimizer phenomenon: A critical review of theory and application. European Journal of Developmental Science, 2(3), 221-235.

Laible, D., Eye, J., \& Carlo, G. (2008). Dimensions of conscience in mid-adolescence: Links with social behavior, parenting, and temperament. Journal of Youth and Adolescence, 37(7), 875-887.

Malti, T., Gasser, L., \& Buchmann, M. (2009). Aggressive and prosocial children's emotion attributions and moral reasoning. Aggressive Behavior, 35(1), 90-102.

Malti, T., \& Latzko, B. (2010). Children's moral emotions and moral cognition: Towards an integrative perspective. New Directions for Child and Adolescent Development, 2010(129), 1-10.

Menesini, E., \& Camodeca, M. (2008). Shame and guilt as behaviour regulators: Relationships with bullying, victimization and prosocial behaviour. British Journal of Developmental Psychology, 26(2), 183-196.

Menesini, E., Sanchez, V., Fonzi, A., Ortega, R., Costabile, A., \& Lo Feudo, G. (2003). Moral emotions and bullying: A cross-national comparison of differences between bullies, victims and outsiders. Aggressive Behavior, 29(6), 515-530.

Nosek, B. A., Banaji, M. R., \& Greenwald, A. G. (2002). E-research: Ethics, security, design, and control in psychological research on the internet. Journal of Social Issues, 58(1), 161176.

Obermann, M. L. (2011). Moral disengagement in self-reported and peer-nominated school bullying. Aggressive Behavior, 37(2), 133-144.

Osgood, D. W., Finken, L. L., \& McMorris, B. J. (2002). Analyzing multiple-item measures of crime and deviance II: Tobit regression analysis of transformed scores. Journal of Quantitative Criminology, 18(4), 319-347.

Paciello, M., Fida, R., Tramontano, C., Lupinetti, C., \& Caprara, G. V. (2008). Stability and change of moral disengagement and its impact on aggression and violence in late adolescence. Child Development, 79(5), 1288-1309. 
Perren, S. (2011). Entwicklungsprobleme im Ablösungs- und Autonomisierungsprozess. In S. Albisser, C. Bieri Buschor, H. Moser, \& K. Kansteiner-Schänzlin (Eds.), Sozialisation- und Entwicklungsaufgaben von Heranwachsenden (Vol. 1, pp. 179-198). Baltmannsweiler, Germany: Schneider Verlag.

Perren, S., Gutzwiller-Helfenfinger, E., Groeben, M., Stadelmann, S., \& von Klitzing, K. (2009). Bully/victim problems in kindergarten: Are they related to moral disengagement in middle childhood? Paper presented at the Biennial Meeting of the Society for Research in Child Development, Boston, April 2009.

Perren, S., Gutzwiller-Helfenfinger, E., Malti, T., \& Hymel, S. (2011). Moral reasoning and emotion attributions of adolescent bullies, victims, and bully victims. British Journal of Developmental Psychology. DOI: 10.1111/j.2044-835X.2011.02059.x.

Perren, S., \& Sticca, F. (2011). Bullying and morality: Are there differences between traditional bullies and cyberbullies? Poster presented at the SRCD Biennial Meeting, Montréal, March 2011.

Pornari, C. D., \& Wood, J. (2010). Peer and cyber aggression in secondary school students: The role of moral disengagement, hostile attribution bias, and outcome expectancies. Aggressive Behavior, 36(2), 81-94.

Pratt, M. W., Hunsberger, B., Pancer, M., \& Alisat, S. (2003). A longitudinal analysis of personal values socialization: Correlates of a moral self-ideal in late adolescence. Social Development, 12(4), 563-585.

Raskauskas, J., \& Stoltz, A. D. (2007). Involvement in traditional and electronic bullying among adolescents. Developmental Psychology, 43(3), 564-575.

Salmivalli, C., \& Voeten, M. (2004). Connections between attitudes, group norms, and behaviour in bullying situations. International Journal of Behavioral Development, 28(3), $246-258$

Schwartz, S. H. (2006). Human values: Theory, measurement, and applications. Revue Française de Sociologie, 47(4), 249-288.

Slonje, R., \& Smith, P. K. (2008). Cyberbullying: Another main type of bullying? Scandinavian Journal of Psychology, 49(2), 147-154.

Smith, P. K., Mahdavi, J., Carvalho, M., Fisher, S., Russell, S., \& Tippett, N. (2008). Cyberbullying: Its nature and impact in secondary school pupils. Journal of Child Psychology and Psychiatry, 49(4), 376-385.

Smith, P. K., \& Slonje, R. (2010). Cyberbullying: The nature and extent of a new kind of bullying, in and out of school. In S. R. Jimerson, S. M. Swearer, \& D. Espelage (Eds.), The international handbook of school bullying (pp. 249-262). Hillsdale, NJ: Lawrence Erlbaum Associates, Inc.

Stassen Berger, K. (2007). Update on bullying at school: Science forgotten? Developmental Review, 27(1), 90-126.

Stern, S. (2004). Studying adolescents online: A consideration of ethical issues. In E. A. Buchanan (Ed.), Readings in virtual research ethics: issues and controversies (pp. 274-287). Hershey, PA: Idea Group, Inc.

Sticca, F., \& Perren, S. (2010). Guilt and perceived severity in cyber and non-cyber bullying scenarios. Paper presented at the E-youth Conference, Antwerp.

Tangney, J. P., Stuewig, J., \& Mashek, D. J. (2007). Moral emotions and moral behavior. Psychology, 58(1), 345-372.

Ttofi, M. M., \& Farrington, D. P. (2008). Reintegrative shaming theory, moral emotions and bullying. Aggressive Behavior, 34, 352-368. 